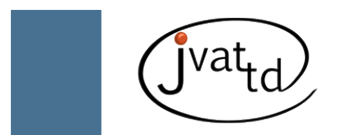

\title{
Cell-free antigens from precocious Paracoccidioides brasiliensis culture induce a typical delayed-type hypersensitivity reaction
}

\author{
Fecchio CJ (1), Dias-Melicio LA (2), Soares AMVC (3), Guimarães S (4), Peraçoli MTS (3), Sartori A (3)
}

(1) Postgraduate Program in Tropical Diseases, Botucatu Medical School, São Paulo State University (UNESP - Univ Estadual Paulista), Botucatu, São Paulo State, Brazil; (2) Department of Pathology, Botucatu Medical School, São Paulo State University (UNESP - Univ Estadual Paulista), Botucatu, São Paulo State, Brazil; (3) Department of Microbiology and Immunology, Botucatu Biosciences Institute, São Paulo State University (UNESP - Univ Estadual Paulista), Botucatu, São Paulo State, Brazil; (4) Department of Parasitology, Botucatu Biosciences Institute, São Paulo State University (UNESP Univ Estadual Paulista), Botucatu, São Paulo State, Brazil.

\begin{abstract}
Cell-free antigens (CFAg) derived from Paracoccidioides brasiliensis have typically been used in immunodiffusion reactions for serodiagnosis or therapeutic follow-up of paracoccidioidomycosis patients. Thus, we investigated the usefulness of CFAg obtained from cultures at different ages, to evaluate cellular immunity by the footpad test, in experimental murine paracoccidioidomycosis. Male mice infected with P. brasiliensis 265 strain were challenged in the footpad with CFAg obtained from four- (4d CFAg) or 11-day-old cultures (11d CFAg). The increase in footpad swelling provoked by $4 \mathrm{~d}$ CFAg and 11d CFAg was similar and showed significant difference in relation to control groups. However, the infiltrate pattern was strikingly different: $4 \mathrm{~d}$ CFAg induced a predominant mononuclear infiltrate whereas $11 \mathrm{~d}$ CFAg provoked a predominant polymophonuclear infiltrate. These different inflammatory patterns were associated with distinct electrophoretic characteristics. By comparison with 11d CFAg, 4d CFAg showed more numerous and intense bands, including a strong one of $43 \mathrm{kDa}$ (gp43). These results suggest that CFAg derived from $\mathrm{Pb} 265$ isolate can be used as a reagent to evaluate cellular immunity; however, the culture's age is critical because only young cultures are able to induce a typical mononuclear infiltrate. The efficacy of this new paracoccidioidin to assay the cellular immunity in infections caused by other $P$. brasiliensis isolates is under investigation.
\end{abstract}

Key words: Paracoccidioides brasiliensis, cell-free antigens, delayed-type hypersensitivity reaction, gp43, murine paracoccidioidomycosis.

\section{INTRODUCTION}

Paracoccidioidomycosis (PCM) is a human systemic mycosis caused by the thermally dimorphic fungus Paracoccidioides brasiliensis, which grows in mycelial form at room temperature and as yeast at $37^{\circ} \mathrm{C}$ in vitro or in infected tissues (1). The infection is endemic in Latin America, with high incidence in Brazil, Colombia, Venezuela and Argentina and manifests as either a systemic condition or as a chronic localized mycosis depending on several factors, including the immunocompetence and genetic profile of the host, fungal burden, exposure time, and the virulence of the fungal strain $(1,2)$.
As in other deep mycoses, cell-mediated immunity has been described as the most important host defense mechanism against this fungus, and a correlation has been found between the severity of the disease and impaired delayedtype hypersensitivity (DTH) response $(3,4)$. Thus, progressive or disseminated forms of the disease are usually associated with depressed cellular immune response and high levels of specific antibodies (3-5).

Several studies have been carried out to search for specific antigens and to standardize tests to evaluate the humoral and cellular immune response in human and experimental PCM. The most used test to evaluate the specific anti- $P$. brasiliensis 
cellular immunity in patients with PCM and in epidemiological studies is the DTH reaction with paracoccidioidin $(4,6)$. The paracoccidioidin that has been classically employed is the Fava-Netto polysaccharide-rich antigen (7). Camargo et al. (8) described a very simple and rapid methodology for extracting cell-free antigens (CFAg) from the yeast form of $P$. brasiliensis. When this preparation was used for the serologic diagnosis of PCM patients, the immunodiffusion tests presented high sensitivity and specificity.

A predominant antigen in this CFAg preparation is a glycoprotein with a molecular weight of $43 \mathrm{kDa}$ (gp43) secreted exocellularly by the infective yeast phase; and among the antigens used in serological methods, gp43 is the most studied P. brasiliensis component $(9,10)$. The gp43 has been described as the immunodominant antigen in PCM and is the main PCM diagnostic antigen, although there are some isolates that do not secrete this glycoprotein (11-15). Gp43 is recognized by all sera from infected patients, particularly in more sensitive assays such as immunoassays, and detected as a circulating antigen in patients $(13,14,16-23)$. Furthermore, gp43 also contains epitopes that elicit positive DTH in mice and humans with PCM $(24,25)$. Indeed, when the P. brasiliensis extract preparation is depleted of gp43, the DTH response is not observed (26). More recently, reports focusing on polymorphism in the PbGP43 gene (which encodes fungal glycoprotein gp43) and on detection of $P$. brasiliensis gp43 gene in patients' sputa brought advances at molecular levels as a genetic marker $(27,28)$.

It has also been shown that animals infected with live fungi strongly recognize gp43 by both humoral and cellular immunity (25). Furthermore, it has been reported that gp43 is also involved in in vitro and in vivo pathogenicity (29).

However, although several studies have employed this antigen to evaluate cellular and humoral immunity, there are no reports in the literature evaluating the effect of different $P$. brasiliensis culture ages on the properties of CFAg preparations. Thus, considering the immunodominant cellular immune response elicited by gp43 present in CFAg extracts, the present work was designed to determine the suitability of CFAg, derived from different culture ages, to evaluate cellular immunity by DTH in murine experimental PCM.

\section{MATERIAL AND METHODS}

\section{Animals}

Six young adult male Swiss mice per group, four weeks old, were used in experiments. The animals were obtained from the Central Animal Facility at the São Paulo State University (UNESP), Botucatu, and provided with water and sterilized food ad libitum throughout the experiments. All the procedures involving animals and their care were conducted in conformity with national and international policies. Moreover, the present study was approved by the Animal Experimentation Ethics Committee of the Botucatu Medical School.

\section{Fungus}

The low-virulence P. brasiliensis strain $265(\mathrm{~Pb}$ 265), which had been kept in the fungal culture collection of the Department of Microbiology and Immunology, at the Botucatu Biosciences Institute, was used throughout this study. $\mathrm{Pb}$ 265 yeast cells were maintained by weekly subcultivation in the yeast-form cells at $35^{\circ} \mathrm{C}$ on $2 \%$ glucose, $1 \%$ peptone, $0.5 \%$ yeast extract and $2 \%$ agar medium (GPY medium), throughout the execution of this work.

\section{Experimental infection}

Yeast cells from six-day-old cultures were washed and suspended in $0.15 \mathrm{M}$ phosphatebuffered saline (PBS pH 7.2). In order to obtain individual cells, the fungal suspension was homogenized with glass beads in a Vortex homogenizer (three cycles of ten seconds). Yeast viability was determined by phase contrast microscopy and bright yeast cells were counted as viable while dark ones were considered not viable (30). Fungal suspensions containing more than $95 \%$ viable cells were adjusted to 25 x $10^{6}$ cells $\mathrm{mL}^{-1}$ based on hemocytometer counts and used in the experiments. Mice were then infected intraperitoneally (IP) with $200 \mu \mathrm{L}$ of the suspension containing $5 \times 10^{6}$ viable yeast cells.

\section{Cell-Free Antigens (CFAg) Preparation}

CFAg were obtained by the methodology described by Camargo et al. (8), with few modifications. Briefly, $\mathrm{Pb} 265$ was grown in GPY medium at $35^{\circ} \mathrm{C}$ for 4 or 11 days. The fungal growth (about $300 \mathrm{mg}$ ) was collected by gently scraping the agarose surface. The cell mass was 
then suspended in $1 \mathrm{~mL}$ of phosphate-buffered saline (PBS), mixed for 30 seconds on a Vortex mixer and immediately centrifuged at $10,000 \mathrm{~g}$ for one minute. The supernatants were sterilized by filtration through millipore $0.22 \mu \mathrm{m}$. Protein concentration was determined according to Lowry et al. (31). Aliquots were kept at $-20^{\circ} \mathrm{C}$ until use. The antigens prepared after 4 and 11 days were denominated $4 \mathrm{~d}$ CFAg and 11d CFAg, respectively.

\section{Delayed-Type Hypersensitivity Test}

The delayed-type hypersensitivity (DTH) reaction was evaluated by the footpad swelling test as previously described (32). Briefly, mice were infected IP with $5 \times 10^{6}$ yeast cells. After 15 days of infection, the animals were challenged in the left hind footpad, with $50 \mu \mathrm{L}$ of suspension containing $50 \mu \mathrm{g}$ of CFAg. The footpad thickness was measured with a calliper immediately before and 24 hours after antigen inoculation. The increase in thickness was calculated and expressed in millimeters. Uninfected mice were injected in the footpads with CFAg or with PBS and used as control groups. Optimal antigen concentration for DTH assays had been determined in preliminary experiments (data not shown).

\section{Histopathology}

Footpad tissue from infected and control mice was collected 24 hours after CFAg inoculation, fixed in 10\% formalin and embedded in paraffin. Five-micrometer sections were obtained and stained with hematoxylin and eosin (HE). The cellular infiltrate pattern and intensity were determined by light microscopy.

\section{Sodium Dodecyl Sulfate Polyacrylamide Gel Electrophoresis (SDS-PAGE)}

SDS-PAGE was performed as previously described (33). Briefly, $54 \mu \mathrm{g}$ of CFAg from 4and 11 day-old cultures of $\mathrm{Pb} 265$ were mixed with the reducing sample buffer containing $62.5 \mathrm{mM}$ TRIS-HCl ( $\mathrm{pH}$ 6.8), 2\% SDS, 10\% glycerol, 10\% 2-mercaptoethanol and 0.005\% bromophenol blue. Molecular weight markers (SDS-6 $\mathrm{H}^{\oplus}$, Sigma-Aldrich, USA) were also included. Glycoprotein bands were detected by silver nitrate staining (34).

\section{Statistical Analysis}

Student's $t$-test was performed to determine the statistical significance of the data at $p<$ 0.05 . Data were expressed as mean \pm SD .

\section{RESULTS}

\section{Characteristics of DTH Reactions Induced by CFAg 4d and CFAg 11d}

To investigate whether the age of $P$. brasiliensis yeast culture could affect the efficiency of CFAg in a DTH reaction, antigens were prepared from 4- and 11-day-old cultures. As shown in Figure 1, 4d and 11d CFAg had induced a similar increase in footpad thickness in the mice at 15 days of infection. However, a clear difference was observed in relation to the cellular infiltrates; 11d CFAg induced predominance of polymorphonuclear cells (PMNs) whereas 4d CFAg induced predominantly mononuclear cell infiltrates (Figure 2). No increase in the footpads was observed in control animals injected with these same antigens (data not shown).

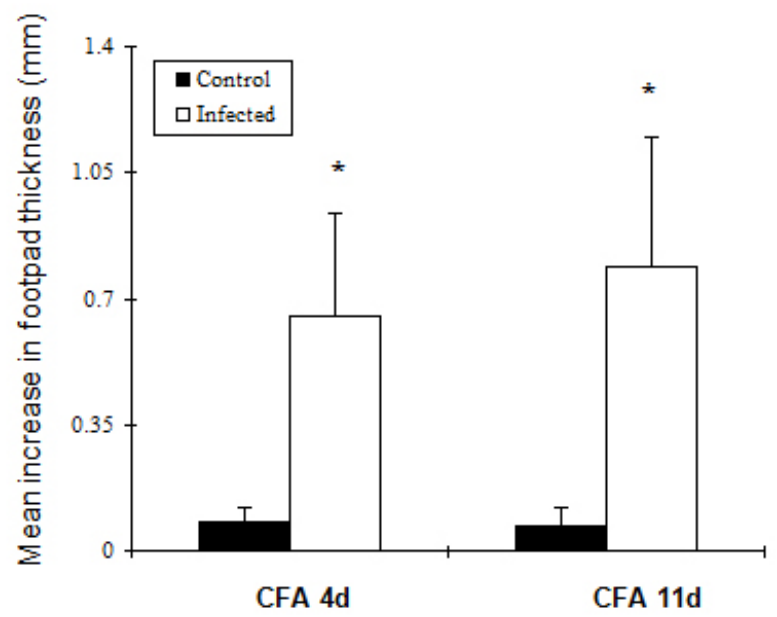

Figure 1. Comparison between reactions induced by $4 \mathrm{~d}$ and $11 \mathrm{~d}$ CFAg. Fifteen days after infection with $5 \times 10^{6} \mathrm{P}$. brasiliensis yeast cells by IP route, mice were injected in the footpad with CFA 265 $(50 \mathrm{mg} / 50 \mathrm{~mL}$ ) obtained from 4-day or 11-day-old culture. After 24 hours the increase in the footpads was determined. The bars depict the mean of six animals \pm SD. * Significantly different $(p<0.01)$ from control group. 


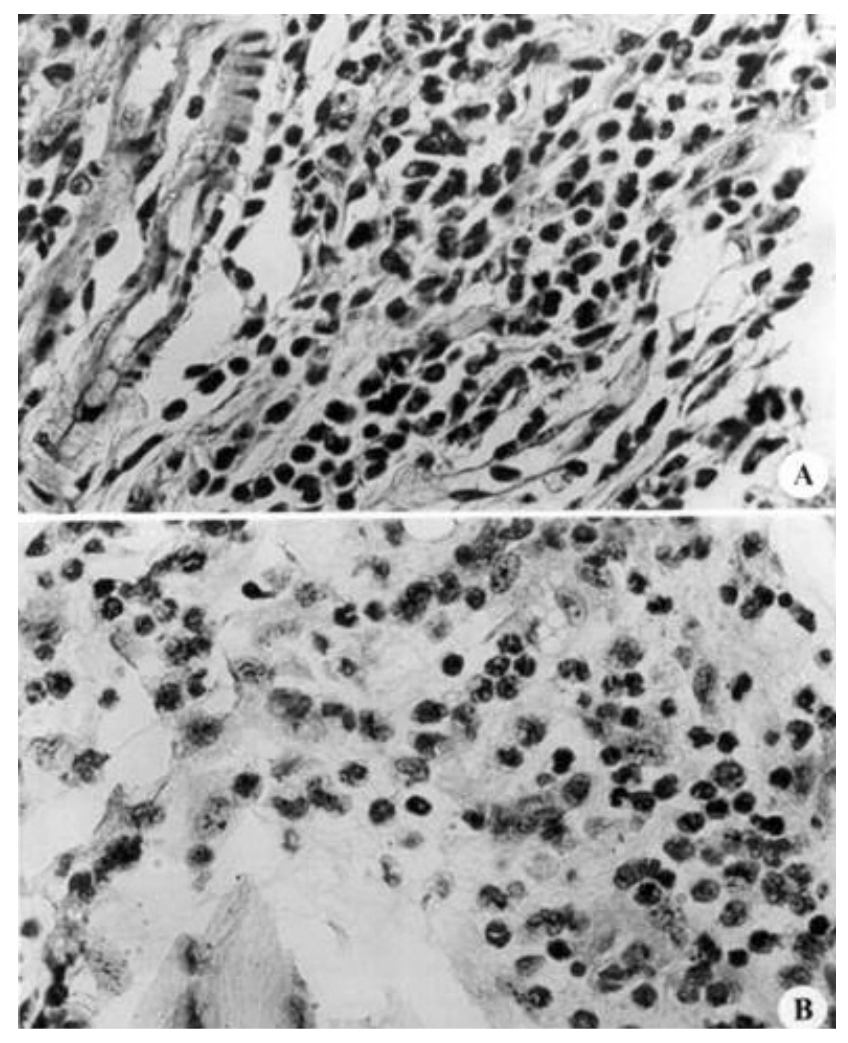

Figure 2. Histopathological analysis of DTH reactions induced by 4d CFAg and 11d CFAg. Fifteen days after IP infection with P. brasiliensis 265, mice were challenged via the footpad with CFAg. Twenty-four hours later, footpad sections were stained and analyzed. (A) Four-day CFAg showing predominance of mononuclear cells (HE 100x) and (B) Eleven-day CFAg showing predominance of polymorphonuclear cells (HE 100x).

\section{Electrophoretic Comparison of $4 d$ CFAg and 11d CFAg}

The differences observed in the DTH reactions described above could be related to quantitative or qualitative composition of the utilized CFAg. To assess this hypothesis, the two CFAg preparations were compared by SDS-PAGE. As can be observed in Figure 3, 4d CFAg showed a broader profile of bands compared to $11 \mathrm{~d}$ CFAg. Considering the bands located at similar positions, the ones present in $4 \mathrm{~d}$ CFAg were always larger than $11 \mathrm{~d}$ CFAg. An interesting finding was the presence of an intense protein band, with an approximate molecular weight of $43 \mathrm{kDa}$, in the $4 \mathrm{~d}$ CFAg. $A$ rather faint band was present at the same position in $11 \mathrm{~d}$ CFAg.

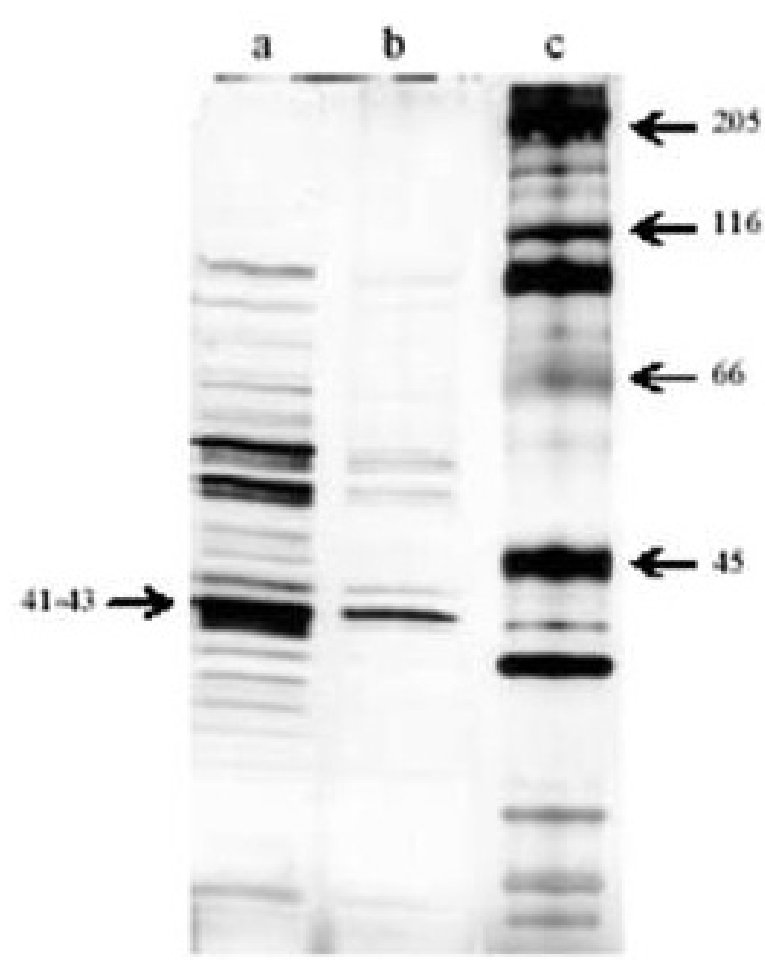

Figure 3. Electrophoretic analysis of $4 d$ CFAg and 11d CFAg. Fifty-four microgram each of 4d CFAg and 11d CFAg were separated by SDS-PAGE under reducing conditions in a 7-14 continuous gradient gel. The bands were visualized by silver staining for glycoproteins. (a) 4d CFAg; (b) 11d CFAg; (c) molecular weight standard ( $\mathrm{BDa})$.

\section{DISCUSSION}

Extraction of CFAg from the yeast forms of $P$. brasiliensis grown in agar slants has been described as a very simple, inexpensive and rapid method to obtain specific antigens from this fungus (8). Tests of this antigenic extract by immunodiffusion showed a high sensitivity and specificity in the serodiagnosis of PCM. To investigate the effect of different $P$. brasiliensis culture ages on the CFAg preparations and the suitability of each as a reagent to evaluate cellular immunity, a DTH reaction was used in a murine model of PCM. As the fungus cultivation duration affected the specificity and sensitivity of serological reactions, we investigated whether this was also true for cellular reactions (8).

The $\mathrm{Pb} 265$ strain, having been widely used in experimental models of paracoccidioidomycosis as the low-virulence standard, possesses the capacity to trigger inflammatory reaction due its 
higher $\beta$-glucan content than those found in other strains (35-37). The results comparing increases in footpads and cellular infiltrates in DTH induced by $4 \mathrm{~d}$ CFAg and $11 \mathrm{~d}$ CFAg produced very interesting results. Footpad enlargements were similarly induced by $4 \mathrm{~d}$ and $11 \mathrm{~d}$ CFAg, but the histopathological analysis indicated a striking difference: a typical DTH reaction, characterized by predominance of mononuclear cells, was associated with $4 \mathrm{~d}$ CFAg. Otherwise, 11d CFAg induced a cellular infiltrate with polymorphonuclear-cell (PMN) predominance. It is tempting to speculate that PMN predominance evoked by $11 \mathrm{~d}$ CFAg could be associated, at least partially, with an Arthus reaction. Alteration in a classical DTH reaction, by an Arthus-type reaction, has been described (38). Experimental evidence in favor of this possibility has been suggested in a murine model of PCM. Fazioli et al. (32) attributed the predominance of PMN, in a DTH reaction using the Fava-Netto antigen, to the contribution of an Arthus-type reaction.

Acceptance of $4 \mathrm{~d}$ CFAg as a reagent to evaluate cellular immunity seems very promising because this preparation is methodologically easy and cheap. In addition, the time required to prepare this antigen, including the interval for fungus growth, is shorter (around eight days) than the classical paracoccidioidins that require cultures aged at least 25 days $(5,8,39)$.

The difference in the inflammatory reaction pattern was also associated with a distinct picture observed by SDS-PAGE analysis. The $4 \mathrm{~d}$ and $11 \mathrm{~d}$ CFAg displayed a similar electrophoretic profile; however, bands in the $4 \mathrm{~d}$ CFAg were strikingly more intense. Also some proteins observed in the $4 \mathrm{~d}$ CFAg were absent in the $11 \mathrm{~d}$ CFAg. The mechanism that generated these two distinct profiles was not evaluated in the present study. However, as the same protein concentration from both antigenic preparations was applied to the gel, the absence or reduced intensity of the bands associated with the 11d CFAg could result from a proteolytic degradation. This possibility is supported by several reports. The disappearance of protein or proteic bands from CFA obtained from older cultures of B-339 P. brasiliensis isolate was previously described (9). Proteolytic activity in P. brasiliensis cultures has also been found (40). This proteolysis could explain the induction by 11d CFAg of an inflammatory reaction distinct from the typical DTH reaction. It is possible that many glycoproteins from $P$. brasiliensis are involved in the cellular immune response. Their degradation could result in the loss of antigenicity for a DTH reaction as has been described for other systems (41).

Another interesting finding was the different intensity in the $43 \mathrm{kDa}$ band found in the two antigens. Four-day CFAg displayed a much more intense band than 11d CFAg. Even though we did not evaluate the identity of this protein, it likely corresponds to gp43. This assumption is based on the molecular weight and also on the high yield of this protein in the original description of CFAg preparation (8). Due to the immunodominance of gp43, it is possible that the induction of a typical DTH by CFAg $4 \mathrm{~d}$ is associated with the presence of this glycoprotein. The abolition of Fava-Netto paracoccidioidin antigenicity by gp43 depletion and the successful use of purified gp43 in DTH reactions reinforce this hypothesis $(24,26)$.

The results presented in this report allow us to suggest the usefulness of CFAg derived from the P. brasiliensis 265 isolate as a reagent to evaluate the cellular immunity, by the footpad test, in experimental PCM caused by this isolate. The use of this antigen to assay the cellular immunity in infections caused by other $P$. brasiliensis isolates is under investigation.

\section{ACKNOWLEDGEMENTS}

The grant of a fellowship by the Coordination for the Improvement of Higher Education Personnel (CAPES) to C. J. Fecchio (postgraduate program in Tropical Diseases, Botucatu Medical School, UNESP) is gratefully acknowledged.

\section{COPYRIGHT}

(C) CEVAP 2011

\section{SUBMISSION STATUS}

Received: February 28, 2011.

Accepted: June 8, 2011.

Abstract published online: June 14, 2011.

Full paper published online: August 31, 2011.

\section{CONFLICTS OF INTEREST}

There is no conflict.

\section{FINANCIAL SOURCE}

The Coordination for the Improvement of Higher Education Personnel (CAPES) provided the financial grants. 


\section{ETHICS COMMITTEE APPROVAL}

The present study was approved by the Ethics Committee of the Botucatu Medical School, UNESP (protocol number 136/98).

\section{CORRESPONDENCE TO}

ALEXANDRINA SARTORI, Departamento de Microbiologia e Imunologia, Instituto de Biociências, UNESP, Rubião Júnior, Botucatu, SP, 18618-970, Brasil. Phone: 55143811 6058. Fax: +55143815 3744. Email: sartori@ibb.unesp.br.

\section{REFERENCES}

1. Restrepo A, Tobón AM. Paracoccidioides brasiliensis. In: Mandell GL, Bennett JE, Dollin R, editors. Principles and practice of infectious diseases. $6^{\text {th }} \mathrm{ed}$. Philadelphia: Elsevier; 2005. p. 3062-8.

2. Franco M, Mendes RP, Moscardi-Bacchi M, RezkallahIwasso M, Montenegro MR. Paracoccidioidomycosis. Baillières Clin Trop Med Commun Dis. 1989;4(1):185220.

3. Brummer E, Castaneda E, Restrepo A. Paracoccidioidomycosis: an update. Clin Microbiol Rev. 1993;6(2):89-117.

4. Musatti CC, Peraçoli MTS, Soares AMVC, RezkallahIwasso MT. Cell-mediated immunity in patients with paracoccidioidomycosis. In: Franco M, Lacaz CS, Restrepo Moreno A, Del Negro G, editors. Paracoccidioidomycosis. Boca Ratón: CRC Press; 1994. p. 175-86.

5. Camargo ZP, Cano LE. Humoral immunity. In: Franco MF, Lacaz CS, Restrepo A, Del Negro G, editors. Paracoccidioidomycosis. Boca Ratón: CRC Press; 1994. p. 187-201.

6. Cermeño J, Cermeño J, Godoy G, Hernández I, Orellán Y, Blanco Y, et al. Epidemiological study of paracoccidioidomycosis and histoplasmosis in a suburb of San Félix city, Bolívar state, Venezuela. Invest Clin. 2009;50(2):213-20.

7. Fava-Neto C, Raphael A. A reação intradérmica com polissacáride do Paracoccidioides brasiliensis na blastomicose Sul-Americana. Rev Inst Med Trop São Paulo. 1961;3(4):161-5.

8. Camargo ZP, Taborda CP, Rodrigues EG, Travassos LR. The use of cell-free antigens of Paracoccidioides brasiliensis in serological tests. J Med Vet Mycol. 1991;29(1):31-8.

9. Puccia R, Schenkman S, Gorin PA, Travassos LR. Exocellular components of Paracoccidioides brasiliensis: identification of a specific antigen. Infect Immun. 1986;53(1):199-206.

10. Stambuk BU, Puccia R, de Almeida ML, Travassos LR, Schenkman S. Secretion of the $43 \mathrm{kDa}$ glycoprotein antigen by Paracoccidioides brasiliensis. J Med Vet Mycol. 1988;26(6):367-73.

11. Camargo ZP, Unterkircher C, Travassos LR. Identification of antigenic polypeptides of Paracoccidioides brasiliensis by immunoblotting. J
Med Vet Mycol. 1989;27(6):407-12.

12. Giannini MJ, Bueno JP, Shikanai-Yasuda MA, StolfMA, Masuda A, Amato Neto V, et al. Antibody response to the $43 \mathrm{kDa}$ glycoprotein of Paracoccidioides brasiliensis as a marker for the evaluation of patients under treatment. Am J Trop Med Hyg. 1990;43(2):200-6.

13. Puccia R, Travassos LR. 43-kilodalton glycoprotein from Paracoccidioides brasiliensis: immunochemical reactions with sera from patients with paracoccidioidomycosis, histoplasmosis, or Jorge Lobo's disease. J Clin Microbiol. 1991;29(8):1610-5.

14. Campos MC, Gesztesi JL, Vincentini AP, Lopes JD, Camargo ZP. Expression and isoforms of gp43 in different strains of Paracoccidioides brasiliensis. J Med Vet Mycol. 1995;33(4):223-7.

15. Berzaghi R, Marques da Silva SH, Pires de Camargo Z. Variable gp43 secretion by Paracoccidioides brasiliensis clones obtained by two different culture methods. J Clin Microbiol. 2005;43(1):491-3.

16. De Camargo Z, Unterkircher C, Campoy SP, Travassos LR. Production of Paracoccidioides brasiliensis exoantigens for immunodiffusion tests. J Clin Microbiol. 1988;26(10):2147-51.

17. Taborda CP, Camargo ZP. Diagnosis of paracoccidioidomycosis by passive haemagglutination assay of antibody using a purified and specific antigengp43. J Med Vet Mycol. 1993;31(2):155-60.

18. Taborda CP, Camargo ZP. Diagnosis of paracoccidioidomycosis by dot immunobinding assay for antibody detection using the purified and specific antigen gp43. J Clin Microbiol. 1994;32(2):554-6.

19. Cisalpino PS, Puccia R, Yamauchi LM, Cano MI, da Silveira JF, Travassos LR. Cloning, characterization, and epitope expression of the major diagnostic antigen of Paracoccidioides brasiliensis. J Biol Chem. 1996;271(8):4553-60.

20. Mamoni RL, Rossi CL, Camargo ZP, Blotta MH. Capture enzyme-linked immunosorbent assay to detect specific immunoglobulin $\mathrm{E}$ in sera of patients with paracoccidioidomycosis. Am J Trop Med Hyg. 2001;65(3):237-41.

21. Albuquerque CF, Marques da Silva SH, Camargo ZP. Improvement of the specificity of an enzymelinked immunosorbent assay for diagnosis of paracoccidioidomycosis. J Clin Microbiol. 2005;43(4):1944-6.

22. Mendes-Giannini MJS, Bueno JP, Shikanai-Yasuda MA, Ferreira AW, Masuda A. Detection of the 43,000-molecular-weight glycoprotein in sera of patients with paracoccidioidomycosis. J Clin Microbiol. 1989;27:2842-5.

23. Gómez BL, Figueroa JI, Hamilton AJ, Ortiz B, Robledo MA, Hay RJ, et al. Use of monoclonal antibodies in diagnosis of paracoccidioidomycosis: new strategies for detection of circulating antigens. J Clin Microbiol. 1997;35(12):3278-83.

24. Saraiva EC, Altemani A, Franco MF, Unterkircher CS, Camargo ZP. Paracoccidioides brasiliensis-gp43 used as paracoccidioidin. J Med Vet Mycol. 1996;34(4):15561. 
25. Taborda CP, Juliano MA, Puccia R, Franco $M$, Travassos LR. Mapping of the T-cell epitope in the major 43-kilodalton glycoprotein of Paracoccidioides brasiliensis which induces a Th-1 response protective against fungal infection in $\mathrm{BALB} / \mathrm{c}$ mice. Infect Immun. 1998;66(2):786-93.

26. Rodrigues EG, Travassos LR. Nature of the reactive epitopes in Paracoccidioides brasiliensis polysaccharide antigen. J Med Vet Mycol. 1994;32(1):77-81.

27. Puccia R, McEwen JG, Cisalpino PS. Diversity in Paracoccidioides brasiliensis. The PbGP43 gene as a genetic marker. Mycopathologia. 2008;165(4-5):27587.

28. Tatibana BT, Sano A, Uno J, Kamei K, Igarashi T, Mikami Y, et al. Detection of Paracoccidioides brasiliensis gp43 gene in sputa by loop-mediated isothermal amplification method. J Clin Lab Anal. 2009;23(2):139-43.

29. Vicentini AP, Gesztesi JL, Franco MF, de Souza W, de Moraes JZ, Travassos LR, et al. Binding of Paracoccidioides brasiliensis to laminin through surface glycoprotein gp43 leads to enhancement of fungal pathogenesis. Infect Immun. 1994;62(4):14659.

30. Dias-Melicio LA, Moreira AP, Calvi SA, Soares AM. Chloroquine inhibits Paracoccidioides brasiliensis survival within human monocytes by limiting the availability of intracellular iron. Microbiol Immunol. 2006;50(4):307-14.

31. Lowry OH, Rosembrough NJ, Farr AL, Randall RJ. Protein measurement with the folin phenol reagent. J Biol Chem. 1951;193(1):265-75.

32. Fazioli $\mathrm{R}$ dos A, Singer-Vermes LM, Kashino SS, Burguer E, De Franco MF, Moscardi-Bacchi M, et al. Delayed-type hypersensitivity response in an isogenic murine model of paracoccidioidomycosis. Mycopathol. 1994;126(3):137-46.
33. Laemmli UK. Cleavage of structural protein during the assembly of the head of bacteriophage T4. Nature. 1970;227(5259):680-5.

34. Wray W, Boulikas T, Wray VP, Kancol JR. Silver staining of proteins in polyacrylamide gels. Anal Biochem. 1981;118(1):197-203.

35. Zacharias D, Ueda A, Moscardi-Bacchi M, Franco M, San-Blas G. A comparative histopathological, immunological, and biochemical study of experimental intravenous paracoccidioidomycosis induced in mice by three Paracoccidioides brasiliensis isolates. J Med Vet Mycol. 1986;24(6):445-54.

36. Singer-Vermes LM, Burger E, Franco MF, Di-Bacchi MM, Mendes-Giannini MJS, Calich VL. Evaluation of the pathogenicity and immunogenicity of seven Paracoccidioides brasiliensis isolates in susceptible inbred mice. J Med Vet Mycol. 1989;27(2):71-82.

37. Silva CL, Alves LMC, Figueiredo F. Involvement of cell wall glucans in the genesis and persistence of the inflammatory reaction caused by the fungus Paracoccidioides brasiliensis. Microbiology. 1994;140(5):1189-94.

38. Crowle AJ. Delayed hypersensitivity in the mouse. Adv Immunol. 1975;20(1):197-264.

39. Fava Netto C. Contribuição para o estudo imunológico da blastomicose de Lutz (blastomicose sul-americana). Rev Inst A Lutz. 1961;21(1):99-194.

40. Carmona AK, Puccia R, Oliveira MCF, Rodrigues EG, Juliano L, Travassos LR. Characterization of an exocellular serine-thiol proteinase activity in Paracoccidioides brasiliensis. Biochem J. 1995;309(1):209-14.

41. Barker SA, Cruickshank CND, Morris JH, Wood SR. The isolation of trichophytin glycopeptide and its structure in relation to the immediate and delayed reactions. Immunology. 1962;5(1):627-32. 